\title{
A SURVEY OF A GROUP OF CHILDREN WITH MENTAL AND PHYSICAL HANDICAPS TREATED IN AN ORTHOPAEDIC HOSPITAL
}

\author{
BY \\ E. P. QUIBELL, ELSPETH STEPHEN and ELIZABETH WHATLEY \\ From Chailey Heritage (Craft School and Hospital), Chailey, Sussex
}

(RECEIVED FOR PUBLICATION JUNE 8, 1960)

In the recent correspondence in the Lancet (Capon, Kirman and Todd, 1959; Quibell, Stephen and Whatley, 1959) and in the non-medical press, great interest has been shown in the treatment of children with mental and physical handicaps. These children represent a hardcore problem, on the borderland between several branches of medicine. It is unfortunate, in our opinion, that in England and Wales the severely mentally handicapped children are not the concern of the education authorities, as is the case in Scotland where they have responsibility for the occupation centres (Younghusband Report on Social Workers, 1959). In the mental deficiency institutions there are some mentally handicapped children with associated physical handicaps; in the children's hospitals there are physically handicapped children with associated mental handicaps. Two of the main groups are children suffering from cerebral palsy and children with spina bifida, associated with myelomeningocele and hydrocephalus. At present, it seems that the placement of these children depends, not on the degree or nature of the physical disability, but on the degree of mental retardation. It may be that the physical handicaps in this borderland group of children tend to be the same, whether they are treated in mental deficiency institutions or in children's hospitals.

We were unable to find conclusive figures of the incidence of spina bifida children with associated mental defect; however, there are figures which suggest that there are quite a number. Hilliard and Kirman (1957) state that of 54 in-patients at the Fountain Hospital with hydrocephalus, 11 had spina bifida. Nash (1957) in his Hunterian Lecture, estimated that there had been an increase of about 500 children a year surviving with congenital spinal palsy since 1954, which in the 10-year period reviewed represents a total of some 5,000 severely paraplegic children. Nash gave no indication of the range of intelligence of these children, but it seems legitimate to assume that the number of educationally sub-normal or ineducable children with spina bifida is increasing.

The incidence of cerebral palsy among children of school age is one to two per 1,000, and we know that approximately $40 \%$ of children with cerebral palsy have I.Q.s below 70. Hilliard and Kirman (1957) gave the number of cerebral palsied children at the Fountain Hospital in 1955 as 228 out of a total of 777 .

\section{Present Inquiry}

In the recent correspondence in the Lancet, at least two writers were successfully treating children with mental and physical handicaps in a general Children's Hospital. No one in this country appears to have reported the results achieved. Wallin (1949) quoted two American studies of the treatment of mental defectives with cerebral palsy, from which it appeared that some mental defectives showed marked improvement in daily living functions after treatment.

An attempt has been made in this paper to evaluate the response to treatment of 40 physically and mentally handicapped children at Chailey Heritage.

Forty educationally sub-normal and ? ineducable children, none of whom had been at Chailey for less than one year were included in the sample; 33 were fairly certainly educationally sub-normal, seven were doubtfully educable. Their ages ranged from 2 to 16 years.

There was one case of poliomyelitis, one case of toxoplasmosis, one case of phenylketonuria with poliomyelitis, 30 cases of cerebral palsy and seven cases of spina bifida. (This is an over-simplification of diagnoses, but it does show that the largest groups were the cases of cerebral palsy and of spina bifida.)

There were the following associated or additional 
handicaps: 36 out of 40 had one or more associated handicaps: 14 had one, 13 had two, eight had three. The range of handicaps was as follows: vision, hearing, speech, epilepsy, and urological conditions (Tables 1 and 2). Fourteen of this group were rated as having an associated somatic hazard: this is a particular physical hazard to which a child is subject because of the main handicap. For example, a spina bifida case is liable to develop pathological fractures or trophic ulcers which may require hospital treatment, sometimes for a long period.

No control groups were used, but as the purpose was to show the progress made by these children in an orthopaedic children's hospital, this is not a major objection. It is possible that more intelligent children might make more and/or quicker progress, and that some of these children will make more progress as methods of treatment change.

The children were assessed in four ways:

(1) An attempt was made to rate the improvement in daily living functions in each child over a period of time. As this was a retrograde study, it turned out to be impossible to rate the children over corresponding periods of time, and we have times for progress made in ambulation only.

(2) An assessment of the present emotional adjustment of a sub-sample was made by one of us (E.W.).

(3) Present educational attainments were supplied by the headmaster.

(4) Data on home conditions were given by the almoner.

\section{Daily Living Function}

The concept of assessing the progress of children in terms of daily living function derives from earlier work at Chailey (Quibell, 1956). This work is an adaptation of the Bellevue scale used in the rehabilitation of adults, and covers all activities essential for daily living. This scale was too detailed for the purpose of a group study, although it is invaluable for the assessment of the individual child; however, the scale used here is based on this work. The
TABLE 1

NUMBER OF ASSOCIATED HANDICAPS IN GROUPS I-IV

\begin{tabular}{|c|c|c|c|c|c|}
\hline \multirow{2}{*}{ Group } & \multirow{2}{*}{ No. } & \multicolumn{4}{|c|}{ Handicaps } \\
\hline & & None & One & Two & Three \\
\hline $\begin{array}{r}\text { I } \\
\text { III } \\
\text { IV }\end{array}$ & $\begin{array}{r}11 \\
10 \\
13 \\
6\end{array}$ & $\begin{array}{l}1 \\
0 \\
\mathbf{3} \\
\mathbf{0}\end{array}$ & $\begin{array}{l}5 \\
2 \\
6 \\
1\end{array}$ & $\begin{array}{l}2 \\
4 \\
3 \\
4\end{array}$ & $\begin{array}{l}3 \\
4 \\
1 \\
1\end{array}$ \\
\hline
\end{tabular}

areas to be assessed were divided into: (1) Speech; (2) ambulation; (3) washing and dressing; (4) feeding; (5) toilet management; (6) fine hand activities.

Two assessments were made of each child; the first was obtained from staff who remembered the child and/or the case notes; the second was made with the help of the staff who are now treating the child. The assessments of the younger children were made with the help of an ad hoc developmental scale in order to allow for age.

The method of scoring was a three-point scale, 0-1-2 in each area, with a minus sign if a child was admitted with no difficulty in the particular area; e.g. if a child came in able to walk he got a in the ambulatory column. 0 indicated total dependence; 1 , partial independence; 2 , independence. The improvement score was arrived at by subtracting the initial score from the final score. These classes are too broad; more classes, more clearly defined are needed. However, points of improvement do represent worthwhile gains in an essential function; worthwhile for the child in terms of independence and morale, and ultimately worthwhile from the economic point of view because such patients then require less nursing care.

The total of 40 children were divided into four groups according to degree of functional independence.

Group I: Children now functionally independent for daily living.

Group II: Children sufficiently independent for placement on the ambulant side but not entirely independent.

Group III: Children requiring ward placement, but showing improvement.

TABLE 2

INCIDENCE OF HANDICAPS

\begin{tabular}{|c|c|c|c|c|c|c|c|}
\hline \multirow{2}{*}{ Group } & \multirow{2}{*}{ No. } & \multicolumn{6}{|c|}{ Handicaps } \\
\hline & & Vision & Hearing & Speech & Epilepsy & Genito-urinary & Total \\
\hline $\begin{array}{r}\text { I } \\
\text { II } \\
\text { III } \\
\text { IV }\end{array}$ & $\begin{array}{r}11 \\
10 \\
13 \\
6\end{array}$ & $\begin{array}{l}6 \\
6 \\
4 \\
3\end{array}$ & $\begin{array}{l}1 \\
3 \\
0 \\
1\end{array}$ & $\begin{array}{l}4 \\
7 \\
4 \\
6\end{array}$ & $\begin{array}{l}3 \\
\mathbf{3} \\
\mathbf{3} \\
\mathbf{1}\end{array}$ & $\begin{array}{l}1 \\
3 \\
4 \\
1\end{array}$ & $\begin{array}{l}15 \\
22 \\
15 \\
12\end{array}$ \\
\hline
\end{tabular}


TABLE 3

I.Q. RANGE

\begin{tabular}{c|c|c|c|c|c}
\hline \multirow{2}{*}{ Group } & \multirow{2}{*}{ No. } & \multicolumn{4}{|c|}{ I.Q. Range } \\
\cline { 3 - 5 } & & $61-70$ & $51-60$ & $41-50$ & Untestable \\
\hline II & 11 & 6 & 5 & - & - \\
III & 10 & 7 & 3 & - & - \\
IIV & 13 & 6 & 2 & 3 & 2 \\
& 6 & 2 & 1 & 0 & 3 \\
\hline
\end{tabular}

Group IV: Children requiring ward placement but considered to be making no worthwhile progress.

Group I. This group consisted of 11 children between the ages of $S$ and 15 , functionally independent for daily living. They were all on the ambulant side and all were in the educationally sub-normal intelligence range (Table 3). Of these 11 children, four had, on the functional scale, maintained their status since admission. This is an indication of the limitations of this scale, i.e. the ceiling is too low; these four children are having treatment to improve their speed and co-ordination in functions in which they were independent on admission. The other seven children have all achieved worthwhile improvement in daily living functions, and four were promoted from the ward side because of such improvement.

Four children in this group were unable to walk on admission and are now fully ambulant. This means that they can walk 100 yards, go up and down gradients, turn, and climb steps or stairs with or without appliances. In fact nine children in this group have no orthopaedic appliances now.

One further comment on this group; we made a general prediction on the future placement of the entire group of 40 , and only one child in this group was judged likely to make open employment. This may be gross underestimation, but even if it is, it does suggest that for many of these children the final goal at present is a basic level in educational skills and as much functional independence as possible. There still remains consideration of the next step when they leave school, e.g. placement in centres for young adult spastics.

Group II. This group consisted of 10 children between the ages of 9 and 16 sufficiently independent for placement on the ambulant side but not entirely independent. These children were all within the educationally sub-normal intelligence range.

All the children in this group have shown some improvement in daily living functions on our criteria, and six were promoted from the ward because of improvement.
Five children were unable to walk on admission and are now fully ambulant.

On the educational side, no child in this group is totally unable to read.

Group III. This group consisted of 13 children between the ages of 2 and 14 requiring ward placement, but showing improvement.

Eleven were treated and only one was able to walk on admission. Of the 11 treated, four are now walking slowly and are making progress, six can walk a few steps with crutches or walkers, but their future progress is considered doubtful; however, to be able to walk a few steps may make the difference between being totally dependent or independent for toilet, one of the most frequent and continuing functions of daily life.

Those under 7 years of age in this group made it of special interest because they included the - ? ineducable children; as Chailey is a school as well as a hospital, the older children are almost by definition not ineducable. It is a small sample, but possibly one can argue that extreme cases can be used as illustrations with some validity. Of these seven children, two were awaiting transfer as ineducable, and two or three others may prove to be ineducable. Five were in the nursery class, and two were on the babies' ward. The teacher's comments on the five in the nursery class were that five improved in speech, four in contacts with other children, and four made some use of nursery apparatus; they fitted into the nursery group reasonably well with younger normal children of their own mental age level. The Sister on the babies' ward said that the two children in her ward seemed reasonably happy.

On the daily living functions improvement chart the assessments were made with the help of the ad hoc developmental scale: in speech, five out of seven showed some improvement.

All were unable to walk on admission; two are now walking alone and are making progress to full ambulation; three are now able to walk a few steps with crutches or walkers; and two are still unable to walk. The stages of ambulation were supplied by the physiotherapists.

Four have made some progress in washing and dressing.

Three were feeding themselves and one 3-year-old phenylketonuric with poliomyelitis affecting the legs was beginning to feed himself.

Three had progressed in toilet training to being clean and dry, i.e. they indicated their toilet needs although they were not, of course, independent.

With regard to fine hand activities, two appeared normal for their mental age; two had made some 
progress; and two, whose hands were affected, because they are quadriplegics, showed no change.

On their social background, three were illegitimate, and two of these who were separated before the age of 3 years remained at Chailey during the holidays, and had no regular visitors; both seemed fairly well adjusted, though it was difficult to assess this, and they were making progress.

These ? ineducable children are the hardcore, and if one can show improvement in these children it seems reasonable to suppose that one can generalize from this to some extent. Our results show that they can improve. They seem to be reasonably adjusted and making some progress in the nursery class, so the possibility is that young mentally and physically handicapped children can be treated in nursery classes with physically handicapped but younger children of their own mental age level. In babies' wards the mental age seems less relevant. We expect that older imbecile children, i.e. from
7 or 8 years, would require a special sub-unit within the hospital (Quibell et al., 1959).

Group IV. This group consisted of six children between the ages of 6 and 15 who were considered to be making no worthwhile progress.

Of these six children, three were within the educationally sub-normal range, three were untestable, and of these, two were almost certainly grossly defective. In the three educationally subnormal children the total physical handicap seemed so gross that physical progress was almost impossible. The two gross defectives were also grossly physically handicapped.

This group is too small to justify conclusions, but it is interesting that half of them are, as far as one can tell, educationally sub-normal (i.e. not ineducable on intelligence tests).

Details for the four groups are set out in Tables 4 to 9 .

TABLE 4

NUMBER OF TREATMENTS IN EACH GROUP

\begin{tabular}{|c|c|c|c|c|c|c|c|c|c|}
\hline \multirow{2}{*}{ Group } & \multirow{2}{*}{ No. } & \multicolumn{8}{|c|}{ No. of Treatments } \\
\hline & & Seven & Six & Five & Four & Three & Two & One & Nil \\
\hline $\begin{array}{r}\text { I } \\
\text { III } \\
\text { IIV }\end{array}$ & $\begin{array}{r}11 \\
10 \\
13 \\
6\end{array}$ & $\bar{z}$ & $\begin{array}{l}\overline{2} \\
-\end{array}$ & $\begin{array}{r}-1 \\
5 \\
2\end{array}$ & $\begin{array}{l}1 \\
3 \\
2 \\
2\end{array}$ & $\begin{array}{l}5 \\
2 \\
1 \\
1\end{array}$ & $\begin{array}{r}5 \\
2 \\
6 \\
-\end{array}$ & $\bar{E}$ & 1 \\
\hline
\end{tabular}

TABLE 5

NUMBER AND NATURE OF TREATMENTS GIVEN IN EACH GROUP

\begin{tabular}{|c|c|c|c|c|c|c|c|c|}
\hline \multirow{2}{*}{ Group } & \multirow{2}{*}{ No. } & \multicolumn{7}{|c|}{ Treatment } \\
\hline & & $\begin{array}{l}\text { Physiotherapy } \\
\text { + R.G. }\end{array}$ & $\begin{array}{c}\text { Occupational } \\
\text { Therapy }\end{array}$ & $\begin{array}{l}\text { Speech } \\
\text { Therapy }\end{array}$ & Drugs & Surgery & Plaster & $\begin{array}{l}\text { Remedial } \\
\text { Teaching }\end{array}$ \\
\hline $\begin{array}{l}\text { I } \\
\text { II } \\
\text { III } \\
\text { IV }\end{array}$ & $\begin{array}{r}11 \\
10 \\
13 \\
6\end{array}$ & $\begin{array}{r}10 \\
9 \\
12 \\
6\end{array}$ & $\begin{array}{l}6 \\
8 \\
6 \\
5\end{array}$ & $\begin{array}{l}4 \\
4 \\
3 \\
6\end{array}$ & $\begin{array}{l}4 \\
6 \\
4 \\
5\end{array}$ & $\begin{array}{l}1 \\
6 \\
5 \\
1\end{array}$ & $\begin{array}{l}4 \\
4 \\
6 \\
2\end{array}$ & $\begin{array}{l}0 \\
2 \\
2 \\
3\end{array}$ \\
\hline
\end{tabular}

TABLE 6

NUMBERS AND TYPES OF APPLIANCES USED IN EACH GROUP

\begin{tabular}{|c|c|c|c|c|c|}
\hline \multirow{2}{*}{ Group } & \multirow{2}{*}{ No. } & \multicolumn{4}{|c|}{ Appliances } \\
\hline & & Orthopaedic & $\begin{array}{l}\text { Protective Cup } \\
\text { and Urinal Bags }\end{array}$ & Sensory* & Total \\
\hline$\underset{\text { III }}{\text { II }}$ & $\begin{array}{r}11 \\
10 \\
13 \\
6\end{array}$ & $\begin{array}{r}2 \\
9 \\
20 \\
7\end{array}$ & $\begin{array}{l}0 \\
4 \\
2 \\
0\end{array}$ & $\begin{array}{l}5 \\
3 \\
4 \\
2\end{array}$ & $\begin{array}{r}7 \\
16 \\
26 \\
9\end{array}$ \\
\hline
\end{tabular}

* Deaf-aids, glasses. 
TABLE 7

DEGREES OF IMPROVEMENT REGISTERED IN EACH GROUP

\begin{tabular}{|c|c|c|c|c|c|c|c|c|c|c|c|}
\hline \multirow{2}{*}{ Group } & \multirow{2}{*}{$\begin{array}{l}\text { No. } \\
\text { Treated }\end{array}$} & \multicolumn{10}{|c|}{ Degrees of Improvement } \\
\hline & & $\begin{array}{c}7 \\
\text { (No.) }\end{array}$ & $\begin{array}{c}6 \\
\text { (No.) }\end{array}$ & $\begin{array}{c}5 \\
\text { (No.) }\end{array}$ & $\begin{array}{c}4 \\
\text { (No.) }\end{array}$ & $\begin{array}{c}3 \\
\text { (No.) }\end{array}$ & $\begin{array}{c}2 \\
\text { (No.) }\end{array}$ & $\begin{array}{c}1 \\
\text { (No.) }\end{array}$ & $\begin{array}{c}0 \\
\text { (No.) }\end{array}$ & $\begin{array}{l}\text { Maintained } \\
\text { (No.) }\end{array}$ & $\begin{array}{l}\text { Promoted from } \\
\text { Ward to School } \\
\text { (No.) }\end{array}$ \\
\hline $\begin{array}{c}\text { II } \\
\text { III } \\
\text { IV }\end{array}$ & $\begin{array}{r}7 \\
10 \\
13 \\
6\end{array}$ & $\begin{array}{l}1 \\
1 \\
-\end{array}$ & $\begin{array}{r}1 \\
1 \\
-\end{array}$ & $\frac{-}{2}$ & $\begin{array}{r}-4 \\
5 \\
-\end{array}$ & $\begin{array}{l}3 \\
3 \\
3 \\
1\end{array}$ & $\begin{array}{r}1 \\
1 \\
2 \\
-\end{array}$ & $\begin{array}{l}1 \\
0 \\
1 \\
-\end{array}$ & $\frac{-}{5}$ & $\frac{4}{-}$ & $\begin{array}{l}4 \\
6 \\
0 \\
0\end{array}$ \\
\hline
\end{tabular}

TABLE 8

SHOWING CHANGE AFTER SPEECH THERAPY TREATMENT

\begin{tabular}{|c|c|c|c|c|c|}
\hline \multirow{2}{*}{ Group } & \multirow{2}{*}{$\begin{array}{c}\text { No. } \\
\text { Treated }\end{array}$} & \multicolumn{4}{|c|}{ Improvement } \\
\hline & & Much Improved & Improved & No Change & Deteriorated \\
\hline $\begin{array}{r}\text { I } \\
\text { II } \\
\text { III } \\
\text { IV }\end{array}$ & $\begin{array}{l}4 \\
4 \\
3 \\
6\end{array}$ & $\begin{array}{r}2 \\
1 \\
1 \\
\end{array}$ & $\begin{array}{r}1 \\
3 \\
2 \\
\end{array}$ & $\frac{-}{6}$ & $\frac{1}{-}$ \\
\hline
\end{tabular}

Assessment of the Emotional Adjustment of a Sub-sample. Seventeen boys were assessed by one of us on present adjustment, using the Maudsley

TABLE 9

PHYSIOTHERAPY AND MOBILIZATION

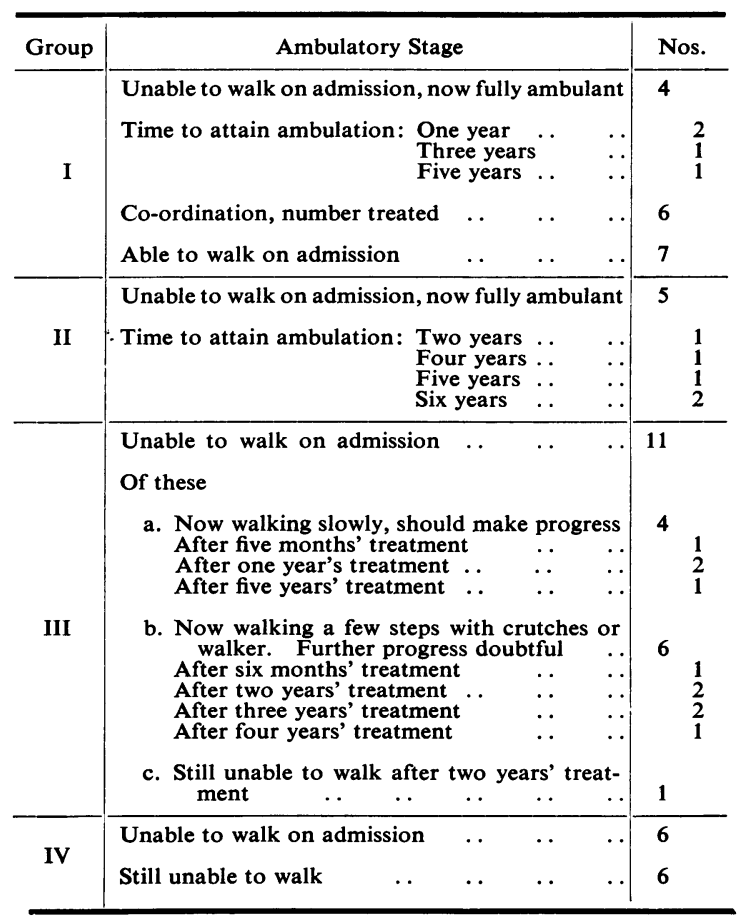

descriptive code (Cameron, 1955) as an adjunct, particularly where the children had not been seen recently. The sub-sample consisted of 13 ambulant boys who were educationally sub-normal and between the ages of 8 and 16, and four more severely handicapped educationally sub-normal boys from the wards over the age of 12 . These boys were rated on a three-point scale as: adjusted, mildly maladjusted and severely maladjusted.

Three were found to be adjusted, 12 mildly maladjusted and two grossly maladjusted.

This is a very small sample, and it would be useful to assess the whole group in this way. The amount of mild maladjustment seems high, but possibly not for a dull physically handicapped population. Dunsdon (1952) found, using teachers' ratings, that of 16 cerebral palsied children with I.Q.s below 70, only two were reasonably stable.

The data for the Maudsley descriptive code were collected by the psychiatrist and psychologist, from the warden, the assistant matron and one staff nurse. It seems worth mentioning that in the opinion of all of us there may be a need for a special unit for these older mentally handicapped (educationally subnormal) children, where they could have a fairly simple routine and occupations geared to their intellectual limitations, and not have to compete with, or hold back those of average and aboveaverage intelligence. It may be impossible to make these doubly handicapped children completely adjusted, but it would be interesting to have an experimental unit in order to see how much one could achieve. These are all educationally sub- 
normal children, so they are catered for on the educational side in small classes.

Sixteen out of these 17 children have some degree of brain damage and were rated as 'immature' on the Maudsley descriptive code; six out of 17 were described as having 'tendency to outgoing aggressive behaviour', eight as having 'tendency to passive withdrawn behaviour'. This is too small a sample from which to draw conclusions, but it is worth noting that the incidence of aggressive and withdrawn behaviour is approximately equal in this group of brain-damaged children.

\section{Present Educational Status}

The 29 educationally sub-normal children in this group had a chronological age range from 8 to 16 years. The reading ages on test ranged from 11 years to under 5 years, with a mean of 7 years (excluding two non-readers). Arithmetic ages on test ranged from 9 years to under 5 years, with a mean of 7 years (excluding one child under 5 who had made no beginning in formal number work). Out of 10 children of 8 years or over with a reading age of under 6 six had speech defects (with or without hearing loss), two had missed much schooling, and two were epileptic. However, of six children of 8 years or over with a reading age of $8+$ (only one had no associated handicap) four had visual defects, four had speech defects, and two had epilepsy. For example, a girl of 10 with a speech defect, a visual defect and pathological temper tantrums, had a reading age of 8 years. Again, arguing from extreme cases, it does seem that some children with the most extraordinary assortment of adverse factors do learn to read.

\section{Home Conditions}

It can be seen from Table 10 that the social factors for the whole group vary considerably. Only very tentative inferences can be made from such a small group, but the following points can, we think, be considered.

There seems no evidence from our figures of a relation between adverse social factors and failure to make progress. The home circumstances of the six children in Group IV, varied from good homes to broken homes with every conceivable adverse factor but actually all these children were either visited by relatives, or went home for part of the holidays, or both. Conversely, four children of the 40 surveyed had no visitors, and remained at Chailey during the holidays. Of these, three were in Group III $(1,2$, and 4 degrees of improvement) and one was in Group II ( 5 degrees of improvement).
TABLE 10

HOME CIRCUMSTANCES OF TOTAL GROUP OF 40 CHILDREN

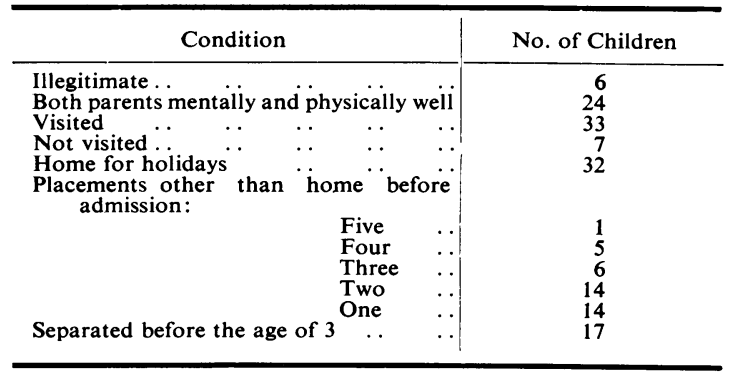

One would expect that had these four children also had good home support, they would have made better progress.

Many of the children with adverse social factors, such as broken homes, early separation from their families, and long and sometimes eventful hospitalization, exhibited only minor degrees of maladjustment, and did show improvement. We suggest that this may be related to the policy (not so rare in many long-stay paediatric hospitals) of meeting their needs on the spot as far as possible, including warm personal relations with individual members of staff, a generally stimulating daily programme, and of maintaining active links with their families through the almoner's department, as much as distance and the overall position of the families allow.

\section{Operations}

In addition to the operations outlined in Table 11 orthopaedic surgery may include other operations to correct deformities in spina bifida cases or to treat pathological fractures.

Neurosurgery may involve excision of a myelomeningocele, drainage of a chronic subdural haematoma, or insertion of a Spitz-Holter valve into the ventricular system in cases of spina bifida with increasing hydrocephalus.

In plastic surgery, trophic ulcers or resultant adherent scars in cases of spina bifida with paraplegia, may call for excision or grafting; palatopharyngeal mobilization and closure may improve speech function and swallowing in cerebral palsy.

\section{Discussion}

These results show that some children with severe mental and physical handicaps do make demonstrable gains in functional independence after treatment in a long-stay children's hospital. The two main groups considered in this study are the mentally handicapped children with (a) cerebral palsy and 
TABLE 11

OPERATIONS ON 13 CHILDREN

\begin{tabular}{|c|c|c|c|c|c|c|c|}
\hline Orthopaedic & No. & Urological & No. & Plastic & No. & Miscellaneous & No. \\
\hline $\begin{array}{l}\text { Eggars for over-active } \\
\text { hamstrings }\end{array}$ & 3 & Bladder neck resection & 1 & $\begin{array}{l}\text { Submandibular gland } \\
\text { excision }\end{array}$ & 1 & Bilateral orchidoplexy & 1 \\
\hline $\begin{array}{l}\text { Grice grafts (stabiliza- } \\
\text { tion of foot) }\end{array}$ & 2 & Urethral plication & 1 & & & Minor operation & 1 \\
\hline $\begin{array}{l}\text { Amputation terminal } \\
\text { phalanges big toes }\end{array}$ & 1 & Suprapubic cystotomy & 1 & & & Tonsillectomy & 1 \\
\hline Tarsal arthrodesis & 1 & $\begin{array}{l}\text { Ileocutaneous uretero- } \\
\text { stomy }\end{array}$ & 1 & & & & \\
\hline Tendon transfer & 1 & & & & & & \\
\hline $\begin{array}{c}\text { Flexor or adductor } \\
\text { tenotomies }\end{array}$ & 3 & & & & & & \\
\hline . $\quad \ldots$ & 11 & & 4 & & 1 & & 3 \\
\hline
\end{tabular}

(b) spina bifida with associated myelomeningocele. It appears that the minimum I.Q. or mental age necessary in order to make useful progress in daily living function is much lower than may have been assumed. Our survey suggests that the children who did not show improvement, could not, because of the severity of the physical handicap, rather than because of their mental dullness. In other words imbeciles may make some response, idiots probably not. Physically and mentally handicapped children require not only medical treatment and special education, but a wide range of training in daily life functions: this study indicates that they can respond to such a programme.

All the evidence suggests that the number of these children who survive is increasing, and therefore knowledge of and planning for their needs are urgent.

In our opinion an essential feature of this kind of work involving as it does, so many forms of treatment, is that there should be one person responsible for the over-all direction and planning of treatment for every child, as recommended in the Piercy Committee report. In this study the medicosocial side of the work was co-ordinated and planned by a paediatrician.

Wall (Director, National Foundation for Educational Research) wrote in The Times Educational Supplement, October 30, 1959: 'If it did not happen daily, it would seem incredible that decisions involving hundreds of thousands of children and many more thousands of pounds are taken with the object of achieving certain ends, and nobody attempts any kind of evaluation of the results more objective than the opinions of those who take the decisions.' We submit, that with the comparatively small and clearly defined group of the mentally and physically handicapped, an enquiry into this matter could be undertaken now. Ours is a crude and retrospective survey, but a more refined, prospective assessment on these or similar lines would in our opinion not be difficult to devise and carry out.

\section{Conclusion}

Of 36 children, 31 showed improvement in the daily living functions, including speech (four of the group of 40 were excluded because they were independent for these functions on admission).

The improvement in ambulation has been analysed as follows: of 26 children unable to walk on admission, nine are now fully ambulant, four are now walking slowly and expected to make progress, six are walking a few steps, while seven are still unable to walk. Nineteen out of 26 children have therefore made worthwhile progress in ambulation.

We are grateful to the many members of the staff at Chailey who co-operated in this survey.

\section{REFERENCES}

Cameron, K. (1955.) Diagnostic categories in child psychiatry. Brit.'J. med. Psychol., 28, 67.

Capon, N. B., Kirman, B. H. and Todd, R. McL. (1959). Queen Mary's and the Fountain. Lancet, 2, 81

Dunsdon, M. I. (1952). The Educability of Cerebral Palsied Children. Chapter 8 . Newnes, London.

Hilliard, L. T. and Kirman, B. H. (1957). The physically handicapped child, p. 233; Morphological syndromes, p. 355. In Mental Deficiency. Churchill, London.

Nash, D. F. Ellison (1957). Congenital spinal palsy-the management of incontinence. Ann. roy. Coll. Surg. Engl., 20, 349.

Quibell, E. P. (1956). The physically handicapped child: Functional assessment of the diability as an aid to planning. Brit. med.J., 2, 991 .

, Stephen, E. and Whatley, E. (1959). Experimental unit for mentally and physically handicapped children. Lancet, 1, 1047. Wallin, J. E. W. (1949). The orthopaedically disabled: Cerebral palsy. In Children with Mental and Physical Handicaps, pp. 419-463. Staples Press, London; Prentice-Hall, New York. Younghusband Report on Social Workers (1959). Para. 215. 